\title{
The Widget Art Gallery
}

\author{
Chiara Passa \\ Rome \\ chiarapassa@gmail.com
}

\section{INTRODUCTION}

The Widget Art Gallery (WAG) is a web-based App that I have built for IPhone, IPad, and the OSXDashboard on Mac. Actually, I think that the WAG is an extremely coherent way in which to show digital and multimedia art.

The virtual alternative to physical space came when I realised that the concept of possession has given way to one of access. So, was born the idea of having an exhibition space available always and everywhere. Due to our needs that seem to be increasingly handheld, the WAG was born on 2009.

The Widget Art Gallery is a mini 3-D single art gallery room that fits into a person's pocket. Every month, the WAG hosts a solo digital art exhibition directly on to a person's mobile device, related and inspired by its dynamic site-specific context.

So, the WAG works both as a sort of Kunsthall showing temporary exhibitions and it works also like a museum because it has a permanent collection, conserving all the past exhibitions inside an online archive always available.

\section{ANALISYS}

I think that a new era is approaching for contemporary galleries and the way in which to exhibit/curate digital art. For a long time, the art system held the monopoly on curated, publicly accessible art. However, the advent of the Internet makes the contemporary galleries re-imagine the nature of the gallery itself, the condition of the exhibition and the curatorial practice on new media art. In fact, many galleries are turning their simple websites into curatorial spaces for contextualising, commissioning and showcasing new artworks. The mobile-show adds a plus valorem: it introduces the possibility to appreciate the artwork in relation to the space also in a private mode.

So, The Widget Art Gallery is often a strange experience. It is a place where people are meant to have a private interaction within the artwork but they could also be surrounded by crowds. In any case, the WAG has both the possibility to be a collective and/or an individual environment

\subsection{The interior design}

The WAG's interior design is inspired by a minimal room of a ninth-century building from which I took a picture of a real empty room. I consider the physical view/frame of the real picture and have figures inside the digital device, helping people to understand and contextualise better the digital artwork inside the mobile space. This is not a paradox in showing digital art because the real picture provides a reference space, like a set of coordinates for the eyes, establishing an illusory axis between the real space and the virtual artwork during the show.

\section{CONCLUSIONS}

The WAG is a virtual display environment that exists on I-Devices where the virtual artwork has neither an inside nor an outside; it is not private, but it is public; it can no longer be only autobiographical, but mostly social. This last peculiarity characterises and distinguishes it from the traditionally visual arts before the advent of the Internet. Many artworks exhibited at the WAG, are made using the Graphics Interchange Format (GIF) that I think it is a great success in art across the board. This is because of its multifunctional and switchable nature between video, photo and a simple static image, GIF gives artists many possibilities of expression and communication.

Diverse artists have exhibited at the widget art gallery, including Lorna Mills, Rea Mcnamara, Rollin Leonard, Françoise Gamma, Manuel Fernandez, Matthew Williamson, Haruko Hirukawa, Yoshi Sodeoka, Daniele Puppi, etc.

\section{REFERENCES}

WAG Website:

http://www.chiarapassa.it/TheWidgetArtGallery.html 

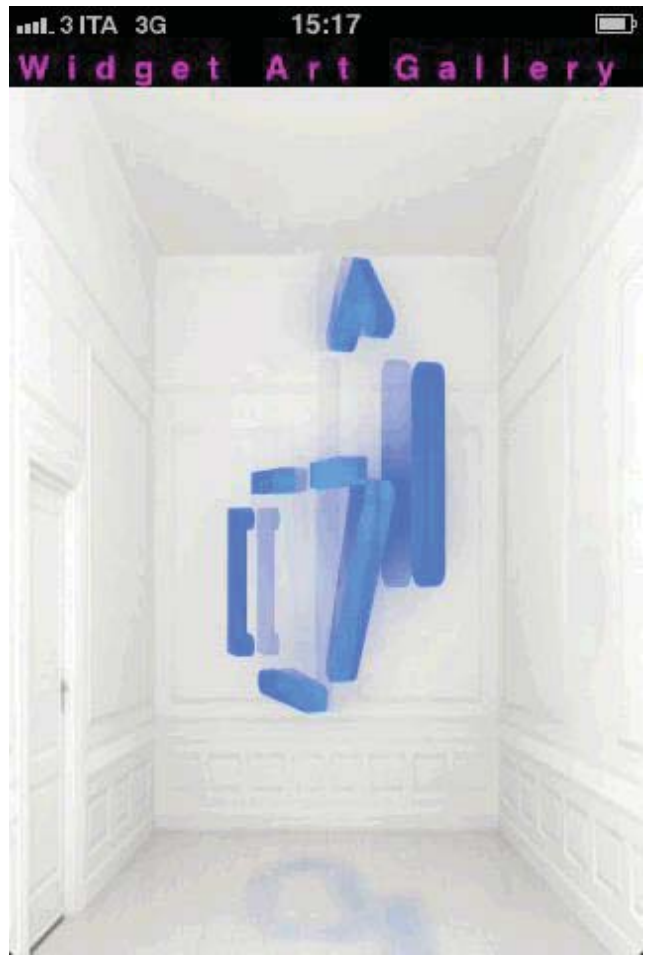

Figure 1: Bill Miller 'A symbol', July 2013

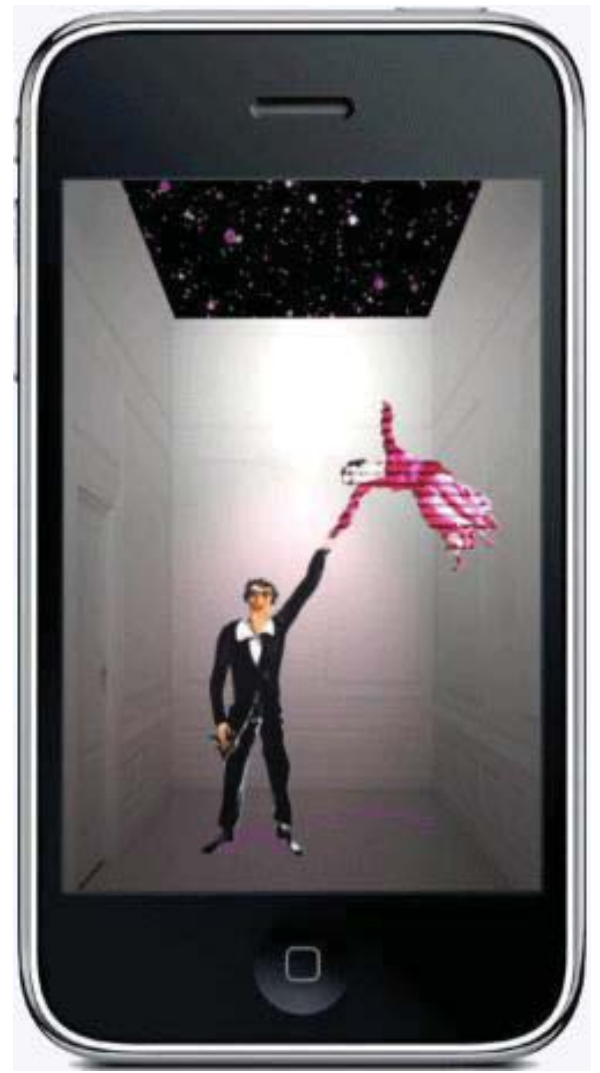

Figure 3: Alberto Gulminetti 'Chagall reloaded-a glitch promenade', December 2013
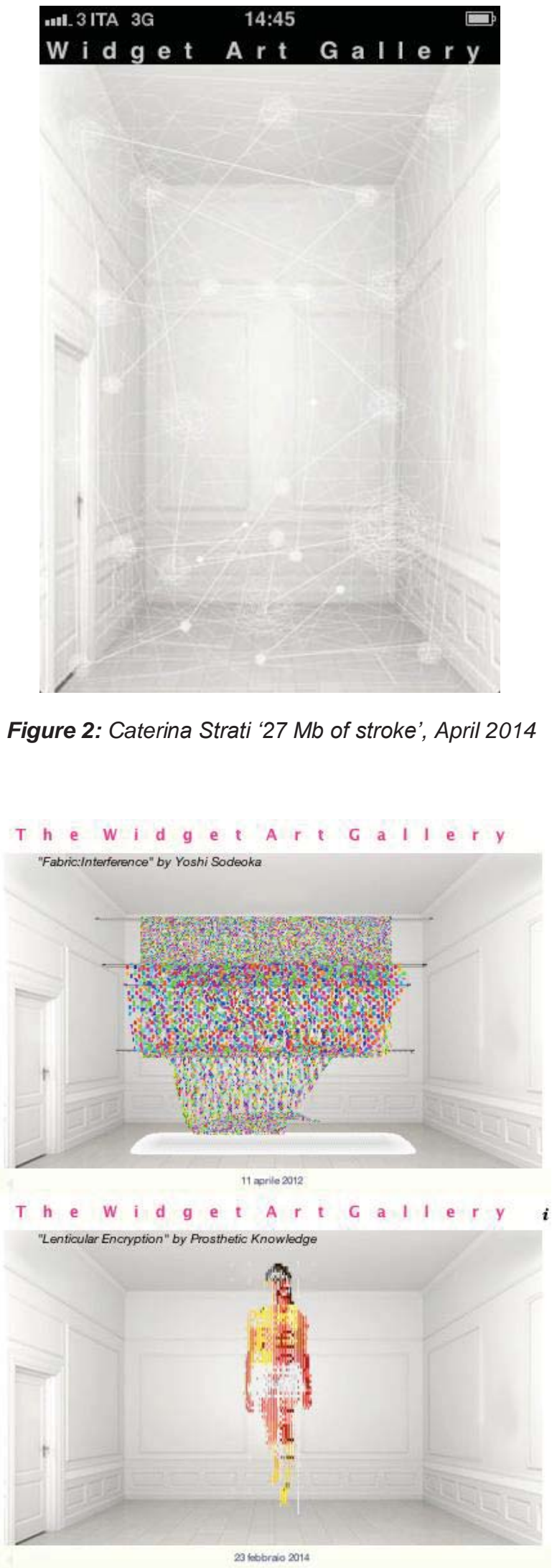

Figure 4: An example of two exhibitions at the WAG OSX-Dashboard 